\title{
DERLEME/REVIEW
}

\section{DÜŞÜK MOLEKÜL AĞIRLIKLI HEPARİN UYGULAMASI}

Nilay TURAÇ*

\author{
Ayla ÜNSAL**
}

\begin{tabular}{lcc}
\hline Alınış Tarihi/Received & Kabul Tarihi/Accepted & Yayın Tarihi/Published \\
15.04 .2019 & 30.11 .2019 & 19.03 .2020 \\
\hline Bu makaleye atıfta bulunmak için/To cite this article: & \\
Turaç N, Ünsal A. Düşük molekül ağırlıklı heparin uygulaması. Anadolu Hemşirelik ve Sağlık Bilimleri \\
Dergisi, 2020; 23(1): 169-175. DOI: 10.17049/ataunihem.553871
\end{tabular}

\section{$\ddot{O} Z$}

Uzun yillardır tıpta trombüs oluşumunu engellemek için antikoagülanlar kullanllır. Antikoagülanlar arasinda en sık kullanılan heparin, standart ve düşük molekül ağırlkkl heparin olmak üzere ikiye ayrllır. Standart heparine göre düşük molekül ağırlıklı heparin avantajlarının fazla olması nedeniyle daha sık kullanılmaktadır. Düşük molekül ă̆ırllkl heparin, membranlardan geçemediğinden genellikle parenteral olarak ve özellikle de subkütan olarak uygulanmaktadır. Subkütan düşük molekül ağırllkll heparin enjeksiyonunda bölgenin seçimine, deri hazırlı̆̆ına, dokuyu kavramaya, iğnenin dokuya giriş açısına, iğnenin hareketine, hava kilidi ve aspirasyon tekniklerinin uygulanma durumlarına, ilacın verilme süresine, bölgeye basınç ve/veya masaj uygulanmasına ve hasta eğitimine dikkat edilmelidir. Hemşirenin subkütan düşük molekül ağırlkkl heparin uygulama öncesi, sırası ve sonrasına iliş̧kin pek çok sorumluğu bulunmaktadır ve bu derleme hemşirenin uygulamaya iliş̧in sorumluluklarını belirtmek üzere yazılmışıtır.

Anahtar Sözcükler: Düşük moleküler ağırllkl heparin; hemşirelik; subkütan

\section{ABSTRACT \\ Responsibilities of Nurses in Subcutaneous Low Molecular Weight Heparin Administration}

For many years, anticoagulants have been used to prevent the formation of thrombosis. The most commonly used heparin among anticoagulants is the standard and low molecular weight heparin. Much of the advantages of low molecular weight heparin compared to standard heparin make it more available. Since low molecular weight heparin cannot cross the membranes, it is usually administered parenterally, and especially as subcutaneous. Attention should be paid to the choice of region in subcutaneous low molecular weight heparin injection, skin preparation, tissue concept, needle penetration into tissue, needle movement, airlock, application of aspiration techniques, duration of drug administration and pressure to site, massage and patient education. The nurse has many responsibilities before, during and after the subcutaneous low molecular weight heparin application.

Keywords: Low molecular weight heparin; nursing; subcutaneous

\footnotetext{
*Sorumlu yazar: Nevşehir Hacı Bektaş Veli Üniversitesi, Semra ve Vefa Küçük Sağlık Bilimleri Fakültesi, (Arş. Gör. Dr.) Orcid ID:0000-0003-4169-6609, E-posta: nilay@ nevsehir.edu.tr

** Kırşehir Ahi Evran Üniversitesi, Sağlık Yüksekokulu, (Prof. Dr), Orcid ID: 0000-0003-3319-1600,

E-posta: aunsal@ahievran.edu.tr
} 


\section{GİRIŞ}

\section{Heparinin tarihçesi}

Antikoagülanlar uzun yillardır tıpta, trombüs oluşumunu engellemek için kullanılır. Antikoagülanlar arasında en sik kullanılan heparin, bir rastlantı sonucu keşfedilmiştir. Bir tıp öğrencisi olan McLean, 1916'da karaciğerden hazırladığı birleşimin kan pıhtılaşmasını önemli ölçüde azalttığını saptamıştır. Howell ise bu inhibisyondan sorumlu olan heparini izole etmiştir ve karaciğerde bulunması sebebiyle hepar sözcüğü ile ilişkilendirerek 'heparin' adını vermiştir. Best ve Jorpes 1935-1937'de heparini saf olarak elde etmiş ve kimyasal yapısını tanımlamıştır. Heparin, 1938'de tıbbi tedavide kullanılmaya başlanmış ve ölüme yol açan ağır tromboembolitik hastalıklarda hayat kurtarıc1 olmuştur (1).

\section{Heparinin çeşitleri}

Günümüzde temel olarak heparin; standart ve düşük molekül ağırlıklı heparin olmak üzere ikiye ayrilır.

\section{Standart Heparin}

Standart heparin, domuz bağırsak veya sığır akciğeri mukoza hücrelerinden elde edilmektedir. Ağırlığı yaklaşık 4.000-30.000 (ortalama 12.000) moleküldür ve yarı ömrü yaklaşı bir saattir (1-3). Standart heparinin antikoagülan aktivitesinin kontrolü, aktive parsiyel tromboplastin zamanı (APTZ) testi ile yapılır. APTZ'nin normal değeri 24-36 saniyedir. Standart heparin uygulandığında bu değerin yaklaşık iki katı uzaması istenir. APTZ testi ile diğer heparinler ve oral antikoagülanların etkinlikleri rutin olarak izlenebilir $(2,4,5)$. Liquemine, nevparin, panheparin, fragmin, heparin nova, calciparine (ticari isimleri) standart heparin örnekleridir (4).

\section{(DMAH)}

2. Düşük Molekül Ağırlıklı Heparin

Düşük molekül ağırlıklı heparinler, mast hücrelerinden sentezlenir ve ticari preparatları domuz bağırsak mukozasından ve sığır akciğerinden elde edilir. Yaklaşık olarak 5000 molekül ağırlığındadır ve yarı ömrü ise yaklaşık olarak 5-6 saattir (4,5). DMAH'ın antikoagülan aktivitesi, standart heparin kullanımında olduğu gibi hastanın durumu ile ilişkili değildir ve DMAH tedavisi herhangi bir test ile izlenmemektedir. Fakat 4 ile 14 gün arası ya da heparin kesilene dek her 2-3 günde bir trombosit sayımı yapılmalıdır (6). Ayrica DMAH'lar standart heparine göre daha az kanama ve daha düşük şiddette trombositopeni oluşturur. $\mathrm{Bu}$ nedenle DMAH'lerin standart heparine göre doz ayarlamas1 daha kolaydır ve daha az kontrol gerektirir. Ancak DMAH, standart heparine göre daha pahalıdır. Venöz tromboembolinin önlenmesinde standart heparin kadar DMAH'lar de etkilidir. Bunun yanında oral antikoagülanın kontrendike olduğu bazı durumlarda, stroke, unstabil anjina, kalp kapağ 1 değişiminden sonra kullanılmaktadır (4,7-9).

DMAH'ler önlem amaciyla kullanıldığında sabit bir dozda uygulanmasına karşın tedavi amacıyla kullanıldığında alınması gereken doz vücut ağırlığına göre ayarlanmaktadır. Laboratuvar izlemi genellikle gerekli değildir. DMAH böbrek yolu ile atılır. Bu nedenle obezite ve böbrek yetmezliği durumlarında laboratuvar izlemi gereklidir (3). Tedavide kullanılan DMAH'lara clexane, fraxiparine, fragmine, clivarine (ticari isimleri) örnek olarak verilebilir. DMAH'ın üstünlükleri şöyle sıralanabilir:

-Daha uygun biyoyararlılık ve farmakokinetik etkiye sahip olmas1,

-Daha uzun yarı ömürlü olması,

-Derialtından günde bir ya da iki kez uygulama kolaylığı bulunması,

-Aktive parsiyel tromboplastin zamanını izleme ve doz ayarlama gereğinin olmaması,

-Heparine bağlı trombositopeninin daha az görülmesi,

-Osteoporoz yapıc1 etkisinin daha az olmas1,

-Tedavinin ayaktan uygulanabilmesi,

-Bazı ülkelerde hastaneye yatış aranmaksızın da uygulanabildiğinden pahalı olmalarına karşın maliyet açısından daha uygun olmasıdır $(4,10)$.

\section{Heparinlerin Kontrendikasyonları}

Heparinler; intrakranial kanamada, malign tümörde, arteriovenöz malformasyonda, aktif iç kanamada, geçirilmiş travma veya derin biyopside, gebelik ve postpartumda, kontrol altına alınmamış hipertansiyonda, aktif veya geçirilmiş peptik ülser gibi kanama riski olan durumlarda, hemofili ve diğer hastalıklar nedeniyle trombosit sayısının $100.000 \mathrm{~mm}^{3}$ 'den daha az olduğu zamanlarda, karaciğer ve böbrek yetmezliğinde, şiddetli diyabet ve enfeksiyonda, hipersensitivite durumlarında kontrendikedir (4,9-12).

\section{Heparinin Yan Etkileri}

Heparinin; hemoraji, trombositopeni, hipersensitive reaksiyonları, geri dönüşümlü alopesia, osteoporoz ve deri nekrozları gibi sistemik yan etkileri bulunmaktadır $(7,13)$. Heparin tedavisinde en önemli risk faktörü kanamadır. Eğer kanama uzun sürerse tedavinin kesilmesi ve kan tranfüzyonu gerekebilir. $\mathrm{Bu}$ nedenle hastalara düzenli olarak APTZ 
bakılmalıdır. Bir diğer önemli risk ise trombositopenidir. Heparin tedavisi sirasinda s1klıkla trombosit sayımı yapılmalı ve en erken zamanda oral antikoagülanlara geçilmelidir (4).

Heparinin sistemik yan etkilerinin yanısıra, enjeksiyon bölgesinde ekimoz, hematom, ağrı gibi lokal yan etkileri de görülmektedir $(3,4,7)$. Ekimoz, deri altına kanın sızması sonucu gözlemlenen renk değişikliği veya morarma olarak tanımlanır. Hematom ise, subkütan tabakada kanın toplanmasıyla cilt yüzeyinden daha derinde ve kitle olarak hissedilebilen renk değişikliği şeklinde tanımlanmaktadır $(7,14)$. Heparinin tedavisinde enjeksiyon bölgesinde hematom, ekimoz ve ağrı gibi yan etkiler bireysel kaynaklı olabildiği gibi, ilacın özelliğine ya da enjeksiyon tekniğine bağlı olarak da gelişebilir $(15,16)$.

\section{Heparinin Uygulanması}

DMAH ve standart heparin, membranlardan geçemediği için parenteral olarak (Subkütan-SC, İntravenöz) uygulanmaktadır. Parenteral uygulamaya ilişkin sorunları ortadan kaldırmak için diğer enjeksiyon yolları araştırılmaktadır. $\mathrm{Bu}$ amaçla heparin ve DMAH'in, transdermal, oral, nazal ve rektal yollardan verilebilecek şekilleri de hazırlanmıştır. Alternatif uygulama amaciyla önceleri heparinin emülsiyonu, lipozomu, çeşitli tuzları ve kompleksleri hazırlanmıştır. Daha sonra ise heparin ile çoğunlukla mikropartiküler sistemler ve emilim artırıcı madde içeren formüller hazırlanmıștır (17).

Hemşire, güvenli ilaç uygulaması için ilaçları temel ilkeler doğrultusunda, uygun teknik kullanarak ve gerekli önlemleri alarak en doğru biçimde uygulamalıdır $(18,19)$. Parenteral ilaç uygulamalarından biri olan SC enjeksiyon uygulamalarında, uygulanan ilaca göre emilimini sağlamak ve komplikasyonları kontrol edebilmek amaciyla uygulama tekniğinde dikkat edilmesi gereken noktalar vardır. Özellikle ardı ardına yapılan heparin enjeksiyonlarından sonra görülen komplikasyonları en aza indirebilmek için uygun teknikle enjeksiyon uygulamak gerekir (18).

\section{Edilmesi Gerekenler}

\section{SC DMAH Enjeksiyonunda Dikkat}

\section{Enjeksiyon Bölgesinin Seçimi}

Literatürde SC uygulama için kullanılan vücut bölgeleri üst kolun diş yüzü, uyluğun ön yüzü, skapula altı ve karın bölgesi olarak sıralanmaktadır (20-22). Karın bölgesinde büyük kas gruplarının az olması, kas içine ilaç verme ve hareketin sinırlı olması ekimoz ya da hematom gelişebilme olasılığını azaltacaktır. Karın bölgesinde de göbeğin $5 \mathrm{~cm}$ 'lik alanının dışında kalan zedelenmemiş, skar dokusu içermeyen bölge seçilmelidir (18). Heparin koldan ve bacaktan uygulandığında buradaki kasların hareketi ekimoz ya da hematom oluşumunu arttırmaktadır (23). Karın bölgesinden operasyon geçirmiş olan hastalarda veya karın bölgesinde yeterli SC doku olmayan durumlarda uyluğun lateral SC dokusu kullanılabilir $(24,25)$. Zeraatkari, Karimi, Shahrzad and Changiz (2005) çalışmalarında uyluk, karın ve kola yapılan enjeksiyonlarda, ekimoz görülme sıklığ açısından bu üç bölge arasında herhangi bir fark bulunmamıştır. Ancak belirtilen araştırmalarda; çalışmaya alınan hastaların kol bölgesine, karın ve uyluk bölgesine enjeksiyon yapilan hastalar olarak üç eşit gruba ayrıldığ görülmektedir. Her bir bölge için enjeksiyon yapılan hasta gruplarının özellikleri bire bir eşitlenmemiştir. Bu nedenle her bireyin kendi kontrol grubu olarak kullanılacağı çalışmalar yapılması önerilmektedir (26).

\section{Enjeksiyon İçin Deri Hazırı̆ı̆ı}

Enjeksiyon yeri antiseptikli solüsyon ile ıslatılmış pamukla dairesel şekilde içten dişa temizlenmeli ve sonra kuruması için beklenmelidir. $\mathrm{Bu}$ uygulamanın gerekçesi, bilindiği üzere deri içine giren patojenlerin sayısının azaltılmasidır $(16,25,27,28)$. Deri hazırlı̆̆ 1 için Isopropyl alkol kullanılmasının vazodilatasyona neden olduğu ve kanamayı arttırdığı öne sürülmektedir. Aynı zamanda isopropyl alkol kullanılmasının pihtı oluşumunu etkilediği ve enjeksiyondan sonra deriyi silmek için kullanıldığında, ekimoz riskini artırdığ düşünülmektedir. Ayrıca alkol cildi sertleştirdiği için de önerilmemektedir. Eğer uygulama alanı gözle görülür biçimde kirliyse su ve sabunla yıkanmalıdır $(29,30)$.

\section{Kavrama \\ 3. Enjeksiyon Uygulamasında Dokuyu \\ SC heparin enjeksiyonunda doku, aktif} olmayan elin baş ve işaret parmakları ile kavranmalı ve kas tabakasindan ayrilarak yükseltilmelidir. Bireyin SC tabakasının kalınlığına göre deri gerdirilmeli veya en az $2 \mathrm{~cm}$ kadar yükseltilmelidir. Eğer SC tabaka çok kalın ise cilt gerdirilmelidir. İğne uzunluğunun kavranmış olan dokunun yarısı kadar uzunlukta olması sağlanmalıdır. Çünkü SC enjeksiyonlar yanlışlıkla kas dokusu içine uygulanabilmektedir. Özellikle abdomen ve uyluk bölgelerinde, iğnenin uzunluğuna uygun SC dokuya girilerek ilacin verilmesi sağlanmalıdır $(20,21,31)$. İlaç verilirken kavranan doku hafifçe serbest bırakılmalıdır. Çünkü ilaç sıkıştırılmış dokuya verildiğinde sinir 
lifleri irrite olur ve hasta da rahatsızlık hisseder. Ancak dokuyu serbest bırakırken iğnenin hareket etmemesine ve SC dokunun kaybolmamasina dikkat edilmelidir (32).

\section{Enjeksiyon Uygulamasında İğnenin Dokuya Giriş Açısı}

Kullanıma hazır enjektörle yapılan SC DMAH uygulamasında iğnenin doku içine giriş açıs1 $90^{\circ}$ olmalıdır. Hasta zayıf olduğunda SC DMAH enjeksiyonu yapılırken yă dokunun gerilmesi gerekmektedir. Özellikle yaşlı hastalarda deri esnekliğini kaybettiği için deri gerdirildiğinde iğnenin deriye girişinin de kolaylaşacağı belirtilmektedir $(20,25,28)$.

\section{Enjeksiyonda İğnenin Hareketi}

SC DMAH enjeksiyonu sırasında iğnenin hareketini azaltmak için dokuya hangi açı ile girildiyse uygulama sonrasında da aynı açı ile dokudan geri çekilmesi gerekmektedir. Bu uygulama, iğnenin hareketini azaltarak doku harabiyetini önleyecektir. Böylelikle enjeksiyon tekniğine bağlı travmalar azalacaktır (22).

\section{Kullanımı}

6. Enjeksiyonda Hava Kilidi Tekniğinin

SC DMAH enjeksiyon uygulanırken enjektör içerisinde 0.1-0.2 $\mathrm{ml}$ hava bulundurulması önerilmektedir. $\mathrm{Bu}$ hava kilidi sayesinde enjektördeki havanın ilacın üstünde kalmasıyla enjektörde kalan son ilacı da havanın iterek vermesi sağlanmaktadır. Böylece ilaç tam doz olarak uygulanmış olacaktır. (23,33). Ayrıca bu teknik sayesinde enjeksiyondan sonra iğne geri çekilirken heparinin cilt altına ve/veya içine sızması önlenerek ekimoz ve hematom gelişme olasılığ1 azaltılacaktır (33).

\section{Durumu}

7. Enjeksiyonda Aspirasyon Uygulanma

İlaç uygulamalarından önce iğne ucunun kan damarında olup olmadığını anlamak için pistonu geri çekerek kan gelip gelmediğini kontrol etme işlemine aspirasyon işlemi denilmektedir. Ancak SC heparin enjeksiyonlarında aspirasyon uygulanması önerilmemektedir. Çünkü, bu uygulamanın iğnenin hareketini arttırarak doku harabiyetine, ekimoz veya hematom gelişimine neden olabileceği ifade edilmektedir (33). Ayrıca, SC heparin enjeksiyonunda aspirasyon işleminin negatif basınç etkisiyle hematoma neden olduğu belirtilmektedir (30).

\section{Enjeksiyonda İlacın Verilme Süresi}

Heparin uygulamasında ilacın yavaşça enjekte edilmesi, enjeksiyondan sonra ise iğnenin dokudan hızlı bir şekilde geri çekilmesi önerilmektedir (32). Zaybak ve Khorshid'in çalışmasında ilacın veriliş süresinin ekimoz gelişimi, ağrn şiddeti ve süresi üzerinde etkili olduğu, ilaç daha uzun sürede verildiğinde ekimozun daha az düzeyde geliştiği, ekimoz büyüklüğü ortalamalarının daha düşük olduğu, ağrı şiddetinin azaldığı ve ağrı süresini kısalttığ saptanmıştır (34). Zaybak ve Khorshid (2005), Chan (2001), Akpınar ve Çelebioğlu'nun (2008) yaptıkları üç farklı çalışmada 10 ve 30 saniyede heparin uygulanmış ve 30 saniyede yapılan heparinin daha az ağriya ve daha küçük ekimoza neden olduğu saptanmıştır (34-36). Yapılan bir diğer çalışmada ise, SC heparin 10 ve 20 saniyede uygulamış ve 20 saniyede yapılan enjeksiyonun daha az ekimoz ve ağriya neden olduğu bulunmuştur (37).

9. Enjeksiyondan Sonra Enjeksiyon Yerine Basınç ve Masaj Uygulanması

Yapılan çalışmalarda enjeksiyondan sonra enjeksiyon bölgesine basınç uygulanması önerilmektedir. SC heparin enjeksiyonundan sonra enjeksiyon yerine basınç uygulanmasının, enjeksiyon yapılan bölgeden kanın geriye gelmesini önlediği ve ekimoz ya da hematom gelişme riskini azalttığı belirtilmektedir $(32,34)$. Heparin uygulamasından sonra yapılması gereken basınç, enjeksiyonu yapan kişinin işaret parmağının rengini açacak kadar olması yeterli ve gereklidir (24).

Literatüre göre heparin uygulandiktan sonra basınç önerilmesine karşın masaj uygulanması kesinlikle önerilmemektedir. Yavaş emilmesi istenen ilaçların emiliminin masaj yoluyla arttırılmasının sakıncalı olması nedeniyle masaj uygulaması heparin gibi ilaç uygulamalarından sonra önerilmemektedir. Ayrica masaj uygulamasinin ekimoz ve hematom oluşumuna neden olduğu belirtilmektedir $(23,33)$.

\section{Rotasyon Uygulanması \\ 10. Seçilen Enjeksiyon Bölgesine} Subkütan DMAH enjeksiyonu uygulanırken doku palpe edilip doğru uygulama alanının ve eğer doku, enjeksiyon için uygun değilse doğru rotasyon bölgesinin belirlenmesi gerekmektedir $(18,21,38)$. Özellikle sürekli insülin veya heparin uygulanan hastalarda, doku hasarına ve emilimde gecikmeye neden olmamak için her enjeksiyonda farklı bir alan kullanılması önerilmektedir $(18,22)$.

\section{SC DMAH Uygulama Basamaklarında Hemşirenin Dikkat Etmesi Gerekenler}

a) Uygulama öncesinde hemşire; düşük riski, anevrizma, serebrovasküler hemoraji, hipertansiyon, pıhtılaşma bozuklukları, yakın 
zamanda geçirilmiş oftalmik ameliyat ya da nöro cerrahi işlemler gibi heparin kullanımına sakıncalı olan durumları bilmelidir. Ayrıca hemşire bireyi, hemoraji riskini arttıran doğum, diyabet, böbrek veya karaciğer hastalığı, ciddi travma, vaskülit ve sindirim sistemi, genitoüriner sistem ya da solunum sisteminde aktif ülser ya da lezyonlar açısından değerlendirmelidir.

b) Heparinle etkileşime giren ilaçlar salisilik asit, steroid olmayan antiinflamatuar ilaçlar, sefalosporinler, antitroid ajanlar ve trombolitiklerdir. Hemşire, uygulama öncesinde hastanın bu tür ilaçları kullanma durumunu bilmelidir (39).

c) Hastanın kimlik tespiti yapılmla1 ve uygulama dozu kontrol edilmelidir.

d) İlaç hazırlamadan önce eller yıkanıp, nonsteril eldiven giyilmelidir.

e) İlaç tepsisi hazırlanarak ilaç kontrol edilmelidir.

f) Doğru hasta belirlenip hastaya işlem açıklanmalıdır.

g) Hastaya uygun pozisyon verilmelidir.

h) Diğer vücut bölgelerine göre daha az kılcal damar içerdiği için karın bölgesi tercih edilmelidir.

i) Bölgesel hasarı en aza indirmek için uygulama yapılacak bölge, göbek deliğinden ya da var olan bir yaradan en az $5 \mathrm{~cm}$ uzakta olmalıdır. Eğer ikinci bir uygulama yapılıyor ise rotasyon tekniği kullanılmalıdır.

j) Belirlenen bölge uygun antiseptikle merkezden başlayarak dairesel hareketle dışa doğru $5 \mathrm{~cm}$ çapında silinmelidir.

k) Uygulamaya hazır olan ilacın içindeki hava çıkarılmamalıdır.

1) Temizlenen dokuya dokunmadan pasif elin işaret ve başparmağı kullanılarak deri hafifçe yükseltilmelidir. Bu esnada hastaya derin nefes alması söylenmelidir.

m) Kullanıma hazır enjektör kalem gibi tutulmalıdır. İğnenin eğimi dışa bakar iken, $90^{\circ}$ 'lik açı ile dokunun gevşek olan noktasından batırılır. Doku zedelenme riski olduğu için piston geri çekilmemeli, yani aspire edilmemelidir.

n) İlaç verildikten sonra iğne girilen açıyla geri çıkarılmalıdır.

o) Doku hasarına sebep olmamak için masaj yapılmamalıdır. Kuru pamuk tamponla bir kaç saniye bölgeye hafifçe basınç uygulanmalıdır.

p) Hastanın rahat pozisyona gelmesine yardım edilmeldir. q) Enjektörün kapağını takma esnasında, iğnenin batmasını önlemek için enjektör kapağı tekrar kapatılmadan uygun şekilde atık kutusuna atılmalıdır.

r) Eller yıkanmalı ve yapılan işlem hemşire gözlem formuna kaydedilmelidir Uygulamadan hemen sonra ilacın adı, dozu, yolu ve zamanı ilaç uygulama belgesi üzerine kaydedilmelidir. Kurumun politikasına göre ilaç uygulama belgesi imzalanmalıdır. Hastanın ilaca yanıtı kaydedilmelidir. İlaca bağlı istenmeyen herhangi bir etki olduğunda kurum politikasına göre hareket edilmelidir (4,19,20,25,27,28, 29,40-42).

\section{Eğitimi}

12. Heparin Tedavisi Alan Hastanın

Hasta eğitiminde broşür gibi eğitim materyalleri kullanılabilir. Hasta eğitiminde şunlar yer almalıdır; İlaç tedavisinin neden/nedenleri açıklanmalıdır. Hasta kullandığı antikoagülan ilacın adını, rengini ve ne zamandır kullandığını bilmelidir. Hasta ve ailesi kanama belirtileri yönünden bilgilendirilmelidir. Aktive parsiyel tromboplastin zamanı değerine belirli aralıklarla baktırılması gerektiği ve normal süresini, hastaneye ne zaman başvuracağ açıklanmalıdır. Diyetteki değişiklikler özellikle de K vitamini içeren besinler APTZ değerini değiştireceği için diyette sabit düzeyde tutulmasının önemi anlatılmalı ve diyetisyen ile işbirliği sağlanmalıdır. Alkol ve antikoagülanın birlikte alınması gastrointestinal kanamaya yol açacağından alkol alımı sınırlandırılmalıdır. Antikoagülan ilaç tedavisi ile birlikte bazı ilaçların alınmaması gerektiği ve nedenleri açıklanmalıdır. Hasta, hekimine antikoagülan ilaç kullandığını belirtmelidir. Hasta yanında antikoagülan ilaç kullandığını belirten kart taşımalıdır $(4,8)$.

Sonuç olarak heparin gibi tedavide geniş kullanım alanı olduğu kadar ciddi yan etkileri de olan ilaçların uygulanmasında doğru teknik ve değerlendirme, istenmeyen yan etkileri azaltabilir ya da tamamen ortadan kaldırabilir. Hemşirenin heparin uygulamasında doğru teknik ve değerlendirme yapabilmesi ise yeterli bilgi, deneyim ve bunları uygulamaya aktarabilmesi ile sağlanabilir( 1,43$)$.

\section{Çıkar Çatışması}

Yazarlar arasında kişisel ve finansal bir çıkar çatışması bulunmamaktadır.

\section{Yazar Katkısı}

Fikir, tasarım, verilerin analizi ve yorumlanması, makalenin hazırlanmasi; NT, AÜ. 


\section{KAYNAKLAR}

1. Özcanl1 D. Antitrombotik tedavi ve hemşirelik fonksiyonları. Yoğun Bakım Hemşireliği Dergisi 2006;10(1):36-42.

2. Crutchfield DB. Low molecular weight heparins. Geriatric Times 2002;3(1):28-32.

3. Willis RL, Sciacca S. Anticoagulant and antiplatel drugs. In Gutierrez K, Queener SF, eds. Pharmaclogy for Nursing Practice. Missouri: St Louis; 2003. p.138-56.

4. Dökmeci İ, Dökmeci H. Sağlık Yüksekokulları için Farmakoloji. İstanbul: İstanbul Tıp Kitabevleri; 2015. p.201-7.

5. Ferhanoğlu B. Antikagülan tedavi. In Altıparmak R, Hamuryudan V, Sonsuz A,Yazıc1, eds. Cerrahpaşa İç Hastalıkları. İstanbul: İstanbul Tıp Kitabevi; 2011. p.319-21.

6. Töbü M. Antikoagülan Tedavi. Ege Üniversitesi Tıp Fakültesi, Erişkin Hematoloji Bilim Dalı Türk Hematoloji Derneği Temel Hemostaz Tromboz Kursu; 2006. p.79-84.

7. McKenry LM, Solerno E. Pharmacology in Nursing. Missouri: St Louis; 2003. p.90-118.

8. Hirsh J. Raschke R. Heparin and low-molecular weight heparin. Chest 2004;126(3):188-9.

9. Hirsh J. O’Donnell M. Eikelboom J.W. Beyond unfractioned heparin and warfarin: current and future advances. Circulation 2007;116(5):552-60.

10. Edmunds M. Introduction Clinical Pharmaglogy. Missouri: St Louis; 2015. p.121-5.

11. Ginsberg JA, Crowther MA. White RH, Ortel TL. Anticoagulation therapy. The American Society of Hematology 2001;2001(1):339-57.

12. Malacaria B, Feloney J. Anticoagulant therapy. Advance for Nursing 2003;33(3):36-42.

13. Memiş S. Hematolojik hastalıklar. In Karadakovan A, Aslan EF, eds. Dahili ve Cerrahi Hastalıklarda Bakım. Ankara: Nobel Kitabevi; 2010. p.157-63.

14. Karadakovan A. Derinin değerlendirilmesi. In Karadakovan A, Aslan EF, eds. Dahili ve Cerrahi Hastalıklarda Bakım. Ankara: Nobel Kitabevi; 2010. p.76-88.

15. Kuzu N, Uçar N. The effect of cold on the occurrence of bruising, hematoma and pain at the injection site in subcutaneous low moleculer weight heparin. International Journal of Nursing Studies 2001;38(1):51-9.

16. Avşar G, Kaşıkcı M. Subkütan heparin enjeksiyonlarında ekimoz, hematom ve ağriyı önlemek için nelere dikkat edilmeli? İstanbul Üniversitesi Florance Nightingale Hemşirelik Dergisi 2012;20(3):239-46.

17. İskenderoğlu C, Acartürk F. Heparin ve Düşük Molekül Ağırlıklı Heparinin alternatif yollardan uygulanması. Anadolu Üniversitesi Bilim ve Teknik Dergisi 2006;7(1):83-95.

18. Craven RF, Hirnle CJ. Jensen S. Fundamentals of Nursing. Philadelphia, Wolters Kluwer
Health/Lippincott Williams \& Wilkins; 2013. p.240-56.

19. Wendy RO. Administration of parenteral medicitaions. In Perry A, Potter P, eds. Nursing Interventions and Clinical Skills. Missouri: St. Louis; 2015. p.597-634.

20. Aştı T, Karadağ A. Klinik Uygulama Becerileri ve Yöntemleri. Adana: Nobel Kitabevi; 2011. p.693762.

21. Sabuncu N, Ay FA. Klinik Beceriler, Sağlığın Değerlendirilmesi, Hasta Bakım ve Takibi. İstanbul: Nobel T1p Kitabevleri; 2015. p.117-39.

22. İnanç $\mathrm{N}$, Hatipoğlu $\mathrm{S}$, Yurt $\mathrm{V}$, Avcı E, Akbayrak N, Öztürk E. Hemşirelik Esasları. Ankara, Damla Matbaacılık; 2003. p.58-67.

23. Ulusoy MF, Görgülü RS. Hemşirelik Esaslar1Temel Kuram, Kavram, İlke ve Yöntemler, Ankara: Çağın Ofset; 1995. p.74-80.

24. Kuzu N. Subkütan heparin enjeksiyonu: Ekimoz, hematom ve ağrı gelişimi nasıl önlenir. Cumhuriyet Üniversitesi Hemşirelik Yüksekokulu Dergisi 1999; 3(2):40-6.

25. Ay FA. Sağlık Uygulamalarında Temel Kavramlar ve Beceriler. İstanbul: Nobel Tip Kitabevi; 2016. p.337-41.

26. Zeraatkari K, Karimi M, Shahrzad MK, Changiz T. Comparison of heparin subcutaneous injection in thigh, arm and abdomen. Canadian Journal Anesthesia 2005;52(1):109-10.

27. Sabuncu N, Ecevit ŞA, Karabacak Ü, Karabacak BG, Şenturan L, Şahin NO ve ark. Hemşirelik Esasları Temel Beceri Rehberi. İstanbul: Medikal Yayıncılık; 2015. p.73-85.

28. Agard RN. Fundamental skills and concepts in patient care. Journal of Health Occupations Education 2015;15(2):9-10.

29. Gray $T$, Miller $H$. Injection technique. The Foundation Years 2008;6(4):252-5.

30. Zaybak A. Subkutan heparin enjeksiyon tekniğine bağlı olarak gelişen komplikasyonların önlenmesi. Ege Üniv. Hemşirelik Yüksekokulu Dergisi 2008;24(2):127-34

31. Akpınar RB, Polat HT, Yaman S, Özer N. Subkutan Heparin Uygulamasına Bağlı Gelişen Ekimoz Hematom ve Ağrının Önlenmesi İçin Hemşirelerin Aldıkları Önlemler. Anadolu Hemşirelik ve Sağlı Bilimleri Dergisi 2010;13(4):19-25.

32. Dougherty L, Lister S. The Royal Marsden Hospital Manual of Clinical Nursing Procedures. Oxford: Wiley- Blackwell; 2015. p 675-789.

33. Kozier B, Erb G. Fundamentals of Nursing. England: Pearson Education Limited; 2016. p.776-854.

34. Zaybak A, Khorshid L. Subcutan heparin uygulamasında ilacın veriliş süresinin ekimoz, hematom ve ağrı üzerine etkisinin incelenmesi. Ege T1p Dergisi 2005;44(2):95-9. 
35. Akpınar R, Çelebioğlu A. Effect of injection duration on bruising associated with subcutaneous heparin: A quasi-experimental within-subject design. International Journal of Nursing Studies 2008;45(6):812-7.

36. Chan H. Effect of injection duration on site-pain intensity and bruising associated with subcutaneous heparin. Journal of Advanced Nursing 2001;35(6):882-92.

37. Jafari S, Bolourchifard F. Comparing the effect of two types injection duration on site pain and bruising associated with subcutaneous heparin. European Journal of Pain 2006;10(1):40-51.

38. Gümüş NY. İlaç etkinliğinde hemşirenin vazgeçilmezliği, I. Uluslararası VII. Ulusal Hemşirelik Kongre Kitabı, İstanbul 2000;134-6.
39. Lehne RA, Rosenthal L. Pharmacology for Nursing Care-E-Book. USA: Elsevier Health Sciences; 2014. p.631-62.

40. Pope BB. How to administer subcutaneous and intramuscular injections. Nursing. 2002;32(1):501.

41. Özdilli K, Özhan F. İlaçların veriliş yolları. In: Sabuncu N. Eds:. Hemşirelik Bakımında İlke ve Uygulamalar. İstanbul: Alter Yayıncılık; 2011. p.65-73.

42. Rushing J. How to administer a subcutaneous injection. Nursing 2004;34(6):32-3.

43. Turaç N, Ünsal A. Hemşirelerin Subkütan Düşük Molekül Ağırlıklı Heparin Enjeksiyonu Uygulamasına İlişkin Bilgi ve Davranışları. Hacettepe Üniversitesi Hemşirelik Fakültesi Dergisi 2018;5(1):1-13. 